\title{
Vigilância Sanitária Municipal do Rio de Janeiro: Considerações Sobre a Aplicabilidade Normativa no Controle de Alimentos
}

\author{
SANITARY SURVEILLANCE IN THE MUNICIPALITY OF RIO DE \\ JANEIRO: CONSIDERATIONS OF THE NORMATIVE \\ APLICABILITY IN FOOD CONTROL
}

\begin{abstract}
Rinaldini Coralini Philippo Tancredi ${ }^{*}$ Orlando Marino Gadas de Moraes (**)

Victor Augustus Marin ${ }^{(* *)}$
\end{abstract}

\section{RESUMO}

As regulamentações no âmbito da Vigilância Sanitária, aplicada à área de alimentos, são oriundas de diferentes esferas hierárquicas de governo, com predominâncias das regulamentações municipais. Em vista disto, resolveu-se identificar e discutir os diferentes atos normativos e os instrumentos legais utilizados pela Vigilância Sanitária na área de alimentos, e a sua aplicabilidade, assim como a competência dos Ministérios da Saúde e Agricultura no controle dos diferentes tipos de alimentos e ainda o quantitativo de documentos legais extraidos pela Vigilância Sanitária Municipal no periodo de 1997 a 2004. Os dados obtidos na Divisão de Apoio Técnico em Vigilância e Fiscalização Sanitária da Cidade do Rio de Janeiro, foram analisados e permitiram a constatação de que, as ações fiscais na área de alimentos são executadas de acordo com os atos normativos disponiveis e através de documentos legais pertinentes e com homogeneidade na relação quantitativa de extração desses documentos, verificando-se, ainda, a predominância do caráter educativo sobre o punitivo nas ações fiscais.

(*) Doutoranda do Programa de Pós-Graduação em Vigiláncia Sanitária (PPGVS) do INCQS/ FIOCRUZ, médica veterinária da Coordenação de Vigilância e Fiscalização Sanitária SMG/RJ, Professora Adjunta do Departamento de Tecnologia de Alimentos - UNIRIO. E-mail: rtancredi@globo.com.

("*) Professor Adjunto da Universidade Federal do Estado do Rio de Janeiro - DTA/UNIRIO.

$\left(^{\star * *}\right)$ Professor do PPGVS do INCQS/FIOCRUZ - Bolsista PRODOC/CAPES. Recebido: 20.6.04. Aprovado: 23.8.04. 


\section{Descritores}

Vigilância Sanitária; Fiscalização Sanitária; Legislação; Alimentos.

\section{ABSTRACT}

Aplicable related lawsin regards to the different hierachical levels at Sanitary Surveillance, show a predominance to the locally bound laws in comparison with national abrangent laws. Nevertheless the objectives of the present study included: aplicability and identification and a description of the instruments used by the Sanitary Surveillance and the different normative actue as well as the competencies envolved in the food control by the Agriculture and Health Ministry and a quantitative demonstration of the legal documents compiled by the Sanitary Surveillance from Rio de Janeiro City between the years of 1997 and 2004. The study of the data obtained with the support of the Sanitary Surveillance's branch in Rio made it possible to conclude that the food relation actions taken are in concordance with the normative laws available to public consultation and regards to legal pertinent documents obtained by the homogeneous quantitative seletion; The current findings are also conclusive in regards to the predominance of educative actions over punitive ones.

\section{Key words}

Sanitary Surveillance; Sanitary Inspection; Legislation; Food.

\section{INTRODUÇÃO}

Dentre as ações e serviços de Saúde Pública, encontra-se a Vigilância Sanitária, cuja competência, segundo o art. $6^{\circ}, \S 1^{\circ}$, da Lei n. 8.080/90, é a de desenvolver ações capazes de eliminar, diminuir ou prevenir riscos à saúde e de intervir nos problemas sanitários decorrentes do meio ambiente, da produção e circulação de bens e também de prestar serviços de interesse da saúde, abrangendo o controle de bens de consumo e execução de serviços que direta ou indiretamente, se relacionem com a saúde em todas as etapas e processos de produção e consumo. Segundo Dallari (2001), esta definição de competência permite interpretar que em nosso País, a atividade que abarca tanto o desenvolvimento do conhecimento científico, quanto a complementação das legislações de proteção à saúde, relacionados à segurança alimentar, encontra abrigo na expressão "Vigilância Sanitária de Alimentos". 
No Brasil, a competência para legislar sobre "proteção e defesa da saúde" é da União, dos Estados, do Distrito Federal e dos Municípios, mas cabe à União apenas o estabelecimento de normas gerais sobre o assunto. Os Estados são competentes, para suplementar a legislação posta pela União, e finalmente, cabe aos Municipios, entidades que formam juntamente com os Estados, no dizer do texto constitucional, a República Federativa do Brasil, legislar sobre todos os assuntos de interesse local (Dallari, 1991).

No direito administrativo do Brasil, além da União, dos estados e dos municipios, os chamados entes menores como as entidades autárquicas, revestem-se de competências diversas cada uma das quais podendo editar determinados atos, visto serem pessoas juridicas de direito público mas com esferas limitadas de ação (Cretella Jr., 1981). A autonomia do Municipio brasileiro está assegurada na Constituição da República para todos os assuntos de seu interesse local (Meirelles, 1993), com autonomia para estabelecer e aprovar seus atos administrativos para fins de administração local como no caso da Vigilância Sanitária Municipal. Nada impede, portanto, que estados e municipios tenham suas próprias legislações, porque a competência de legislar sobre a proteção à saúde é concorrente, conforme art. 24, inciso XII da Constituição Federal (Carvalho, 2004).

Costa e Rozenfeld (2000), reafirmam a Vigilância Sanitária como a forma mais complexa de existência da Saúde Pública, uma vez que suas ações, de natureza eminentemente preventivas perpassam todas as práticas médico-sanitárias: promoção, proteção, recuperação e reabilitação da saúde. A Vigilância Sanitária atua sobre fatores de risco associados a produtos, insumos e serviços relacionados com a saúde, com o ambiente e com o ambiente de trabalho, com a circulação internacional de transportes, cargas e pessoas.

Busca-se neste trabalho, identificar e descrever a evolução dos atos administrativos enquanto normas aplicadas à Vigilância Sanitária, no Sistema Federativo Brasileiro, explicitando as formas de apresentação das regulamentações sanitárias, em especial na área de alimentos, com ênfase no periodo após aprovação da Lei Orgânica da Saúde, em 1990. Também discute-se as inter-relações nas diferentes esferas de governo e na aplicabilidade normativa da Vigilância Sanitária do Municipio do Rio de Janeiro. O estudo destaca ainda a condição de autonomia municipal frente à aprovação e aplicação das normas municipais, e os instrumentos legais utilizados na aplicação das normas para fazer com que sejam cumpridas.

\section{METODOLOGIA}

Foi realizada a análise bibliográfica e documental, como forma de identificar e classificar os atos legais e os instrumentos elaborados em 
obediência a estes atos, utilizados nas ações fiscais da Vigilância Sanitária Municipal do Rio de Janeiro. Foi também executado um levantamento nos dados estatísticos relativos aos anos de 1997 a 2004, obtidos na Divisão de Apoio Técnico, da Coordenação de Vigilância e Fiscalização Sanitária, e com base nele identificou-se os tipos de atos mais utilizados ou citados nos documentos extraidos nas ações fiscais.

\section{RESULTADOS E DISCUSSÃO}

$\mathrm{Na}$ área de alimentos, aplica-se no Municipio do Rio de Janeiro o Decreto n. 6.235, de 30 de outubro de 1986, que aprovou o "Regulamento Saúde Individual e Coletiva no Tocante a Alimentos e à Higiene Habitacional e Ambiental da Cidade do Rio de Janeiro", que teve por base o Decreto-Lei Federal 986/69, sobre as "Normas Básicas de Alimentos". O Decreto n. $6.235 / 86$ possui 287 artigos e define os tipos de documentos legais a serem extraidos na verificação de irregularidades nos estabelecimentos fixos ou não, relacionados com a produção/comercialização de alimentos.

De acordo com Cartana (2000), a Vigilância Sanitária detém a propriedade da averiguação do ato ou fato contrários às normas sanitárias em decorrência do controle que lhe é atribuido por diversos ordenamentos com procedência na própria Constituição Federal, somada essa competência ao fato de ser investida de Poder de Policia, o qual acresce às prerrogativas de função de seus agentes fiscais sanitários, o atributo da função fidedigna, o que autoriza a fazerem afirmações oficiais sobre o objeto em averiguação, reduzindo a termo, lavrando autos, emitindo pareceres técnicos e juizos a respeito.

Os Estados e Municípios são competentes, para suplementar a legislação sanitária aprovada pela União, cabendo aos Municipios, parte da República Federativa Brasileira, aprovar e aplicar regulamentações sobre assuntos de interesse local, no sentido de preservar a saúde de seus municipes. A legislação sanitária vigente serve de parâmetro para traçar limites de controles. As regulamentações sanitárias, também denominadas leis no aspecto genérico, podem apresentar-se sob diferentes formas quanto à origem, ao conteúdo, à hierarquia e assim, diferenciando-se também suas aplicabilidades.

A validade ou competência do ato administrativo emana do poder atribuido ao agente administrativo para o desempenho de suas funções no interesse público. Para cada ato administrativo existe uma forma própria 
no que diz respeito à hierarquia, origem, extensão territorial e conteúdo. As leis podem ser, de forma geral, complementares e ordinárias, e os decretos facilitam a sua aplicação. O Decreto-lei tem força de lei, é um ato de força, aprovado pelo executivo, sem aprovação do legislativo; um exemplo deste tipo de ato é o Decreto-lei n. 986, de 21 de outubro de 1969, aprovado por ministros militares, que instituiu as Normas Básicas sobre Alimentos, em todo o Território Brasileiro, embora considerada Lei do Ministério da Saúde. Atualmente este tipo de procedimento, pela sua urgência e relevância (art. 62 da Constituição Federal), passou a ser denominado Medida Provisória, forma pela qual foi criada a Agência Nacional de Vigilância Sanitária (ANVISA). Lei é norma juridica obrigatória, editada pelo legislativo e publicada após sanção do executivo. Dentre as leis antigas ainda vigentes na área de alimentos temos a Lei n. 1.283, de 18 de dezembro de 1950, do Ministério da Agricultura, regulamentada pelo Decreto n. 30.691, de 29 de março de 1952, que aprovou o Regulamento da Inspeção Industrial e Sanitária de Produtos de Origem Animal, em todo o território nacional.

A organização constitucional do Sistema Nacional de Saúde prevê que "as ações e serviços de saúde" integram uma rede regionalizada e hierarquizada num Sistema Único de Saúde, conforme art. 198 da Constituição Federal vigente, deixando claro a competência das três esferas de poder público da federação: União, Estados e Municípios. Também prevê que a obrigação de editar normas de "proteção e defesa da saúde" é competência concorrente dessas mesmas esferas. Isto significa que, a União deve produzir normas gerais, que devem ser suplementadas pelas normas editadas pelo Estado, que por sua vez, serão complementadas através de normas elaboradas pelos Municipios (Silva, 1997). Assim o Decreto-lei n. 986, de 21 de outubro de 1969, por tratar-se de legislação federal, e por aprovar assunto de interesse nacional. Em obediência a este Decreto-Lei foi aprovado pela Secretaria Estadual de Saúde do Rio de Janeiro, o Decreto n. 6.538, de 17 de fevereiro de 1983, que estabeleceu regulamento sobre Alimentos, Higiene e Fiscalização, em todo o Estado do Rio de Janeiro. No âmbito municipal encontra-se vigente o Decreto n. 6.235, de 30 de outubro de 1986, da Secretaria Municipal de Saúde do Rio de Janeiro, que aprova o Regulamento da Defesa e Proteção da Saúde no Tocante a Alimentos e à Higiene Habitacional e Ambiental do Municipio do Rio de Janeiro, muito semelhante em seu contexto ao Decreto n. 6.538/83 da Secretaria Estadual de Saúde, mas diferindo deste por apresentar uma ampliação das informações contidas nas normas reguladoras, facilitando a aplicabilidade nas ações de inspeção sanitária da Vigilância Sanitária da Cidade do Rio de Janeiro (Quadro I). 
Quadro I: Formas de apresentação das Disposições Normativas Sanitárias, quanto à sua origem, conteúdo/aplicabilidade, de ordem geral e nas ações de Vigilância Sanitária

\begin{tabular}{|c|c|c|}
\hline Tipo & Origem & Conteúdo/Aplicabilidade \\
\hline Lei & $\begin{array}{l}\text { Emana do Poder Legisla- } \\
\text { tivo (Câmara de Senado- } \\
\text { res, Deputados e } \\
\text { Vereadores) }\end{array}$ & $\begin{array}{l}\text { Estabelece uma regra, um } \\
\text { direito ou uma exceção de } \\
\text { caráter geral ou específico }\end{array}$ \\
\hline Decreto & $\begin{array}{l}\text { Competência exclusiva } \\
\text { dos Chefes do Executivo } \\
\text { (Presidente, Governado- } \\
\text { res e Prefeitos) }\end{array}$ & $\begin{array}{l}\text { Regulamenta os assuntos } \\
\text { relacionados às leis } \\
\text { existentes. É a determina- } \\
\text { ção formal da autoridade }\end{array}$ \\
\hline $\begin{array}{c}\text { Decreto-lei } \\
\text { (atual Medida Provisória) }\end{array}$ & $\begin{array}{l}\text { Emana do Poder Executi- } \\
\text { vo (Chefe de Estado) e } \\
\text { não do Poder Legislativo }\end{array}$ & $\begin{array}{l}\text { É um diploma normativo } \\
\text { pela manifestação do } \\
\text { Presidente da República, } \\
\text { tem eficácia de Lei }\end{array}$ \\
\hline Resolução & $\begin{array}{l}\text { Competência de autorida- } \\
\text { des outras que não o } \\
\text { Chefe do Executivo } \\
\text { (Ministros/Secretários/ } \\
\text { Colegiados) }\end{array}$ & $\begin{array}{l}\text { Ato com que se formaliza } \\
\text { decisão de Orgão } \\
\text { Colegiado, com instruções } \\
\text { quanto à aplicação de leis } \\
\text { ou regulamentos impondo } \\
\text { uma ordem ou estabelecen- } \\
\text { do medidas }\end{array}$ \\
\hline Portaria & $\begin{array}{l}\text { Competência de autorida- } \\
\text { des outras que não o } \\
\text { Chefe do Executivo } \\
\text { (Chefes de Orgãos, } \\
\text { Repartições ou Serviços) }\end{array}$ & $\begin{array}{l}\text { Formaliza atos administrati- } \\
\text { vos: nomeaçōes, designa- } \\
\text { ções, sindicâncias, } \\
\text { inquéritos ou processos }\end{array}$ \\
\hline Circular & $\begin{array}{l}\text { Competência das Chefias } \\
\text { subordinadas ao Poder } \\
\text { Legislativo ou Executivo }\end{array}$ & $\begin{array}{l}\text { Comunicação de teor } \\
\text { uniforme encaminhada a } \\
\text { um conjunto de pessoas } \\
\text { identificadas por uma } \\
\text { caracteristica comum }\end{array}$ \\
\hline Ordem de Serviço & $\begin{array}{l}\text { Competência das Chefias } \\
\text { de Orgãos, Repartições } \\
\text { ou Serviços }\end{array}$ & $\begin{array}{l}\text { Ato administrativo que } \\
\text { disciplina e uniformiza o } \\
\text { serviço de uma Repartição }\end{array}$ \\
\hline Instrução Normativa & $\begin{array}{l}\text { Expedidos pelos Ministros } \\
\text { de Estado }\end{array}$ & $\begin{array}{l}\text { Instrui para a execução de } \\
\text { leis, decretos e regula- } \\
\text { mentos }\end{array}$ \\
\hline
\end{tabular}

Fonte: Cunha, 2003; Meirelles, 1993. 
Os documentos passiveis de serem extraidos nas ações de controle ou fiscais em Vigilância Sanitária, na área de alimentos conforme o quadro II são: Termo de Visita Sanitária (TVS), identifica e descreve o estabelecimento, identifica o órgão fiscalizador e os agentes, e especifica o motivo da ação fiscal; Termo de Intimação (TI), descreve as exigências estruturais e emergenciais do estabelecimento, e fixa prazos para cumprimento; Termo de Apreensão e Inutilização (TAI), identifica os produtos apreendidos ou inutilizados, geralmente está vinculado ao Auto de Infração e Multa; Auto de Infração (AI), cita 0 artigo infringido e descreve a infração cometida e o valor da penalidade; Edital de Interdição (EI), identifica o estabelecimento e o local, total ou parcialmente identificado e os prazos da interdição; Termo de Apreensão de Amostra para Análise (TAAA), identifica o produto a ser colhido para análise, o motivo da colheita, as condições do produto e o tipo de análise (Quadro II).

\section{Quadro II - Caracterização, aplicação e função dos instrumentos legais utilizados nas ações fiscais da Vigilância Sanitária municipal do Rio de Janeiro}

\begin{tabular}{|c|c|c|c|}
\hline Tipo & Caracterização & Aplicação & Função \\
\hline $\begin{array}{l}\text { Termo de Visita } \\
\text { Sanitária (TVS) }\end{array}$ & $\begin{array}{l}\text { Documento que registra o } \\
\text { motivo da visita ocorrências } \\
\text { e recomendações }\end{array}$ & $\begin{array}{l}\text { Em toda visita de inspeção } \\
\text { sanitária, no ato do } \\
\text { comparecimento }\end{array}$ & $\begin{array}{l}\text { Informativa, } \\
\text { descritiva e } \\
\text { orientadora }\end{array}$ \\
\hline $\begin{array}{l}\text { Termo de } \\
\text { Intimação (TI) }\end{array}$ & $\begin{array}{l}\text { Descreve as exigências } \\
\text { elou correçōes e o prazo } \\
\text { concedido para o } \\
\text { cumprimento }\end{array}$ & $\begin{array}{l}\text { Quando houver neces- } \\
\text { sidade de cumprimento } \\
\text { de exigências ou correções }\end{array}$ & $\begin{array}{l}\text { Preventiva } \\
\text { e corretiva }\end{array}$ \\
\hline $\begin{array}{l}\text { Auto de } \\
\text { Infração (Al) }\end{array}$ & $\begin{array}{l}\text { Instrumento coercitivo } \\
\text { para aplicação inicial de } \\
\text { penalidade prevista em } \\
\text { regulamento }\end{array}$ & $\begin{array}{l}\text { Na verificação de infração } \\
\text { que exija aplicação imediata } \\
\text { de penalidade ou de } \\
\text { intimação não cumprida }\end{array}$ & $\begin{array}{l}\text { Preventiva } \\
\text { e punitiva }\end{array}$ \\
\hline $\begin{array}{l}\text { Edital de } \\
\text { Interdição (El) }\end{array}$ & $\begin{array}{l}\text { Documento que permite } \\
\text { interdição temporária ou } \\
\text { definitiva, parcial ou total } \\
\text { do estabelecimento }\end{array}$ & $\begin{array}{l}\text { Não cumprimento integral } \\
\text { do Tl em segunda } \\
\text { instância, desobediência } \\
\text { grave aos requisitos } \\
\text { higiênico-sanitários }\end{array}$ & $\begin{array}{l}\text { Preventiva } \\
\text { e punitiva }\end{array}$ \\
\hline $\begin{array}{l}\text { Termo de } \\
\text { Apreensão e } \\
\text { Inutilização ou } \\
\text { Depósito } \\
\text { (TAl/TAD) }\end{array}$ & $\begin{array}{l}\text { Termo que permite } \\
\text { apreender e inutilizar ou } \\
\text { manter em depósito } \\
\text { gêneros alimenticios } \\
\text { impróprios ou suspeitos } \\
\text { de impropriedade }\end{array}$ & $\begin{array}{l}\text { Na inutilização de } \\
\text { produtos impróprios para } \\
\text { consumo ou em depósito } \\
\text { para posterior deliberação }\end{array}$ & $\begin{array}{l}\text { Preventiva } \\
\text { e punitiva }\end{array}$ \\
\hline $\begin{array}{l}\text { Termo de } \\
\text { Apreensão de } \\
\text { Amostra para } \\
\text { Análise (TAAA) }\end{array}$ & $\begin{array}{l}\text { Termo que permite colher } \\
\text { amostras para análise } \\
\text { laboratorial }\end{array}$ & $\begin{array}{l}\text { Na colheita de amostras } \\
\text { de alimentos para análise } \\
\text { laboratorial }\end{array}$ & $\begin{array}{l}\text { Preventiva, } \\
\text { orientadora } \\
\text { de registro }\end{array}$ \\
\hline
\end{tabular}

Fonte: Decreto Municipal do Rio de Janeiro n. $6.235 / 86$ e Resolução Municipal do Rio de Janeiro N. 492/94. 
A ação de fiscalizar ou inspecionar alimentos ou serviços de alimentação, com o propósito de prevenir riscos à saúde do consumidor, é competência do Sistema Único de Saúde, e um serviço de rotina, podendo ser também desencadeada a partir de uma denúncia, de identificação de uma situação de agravo à saúde, para instruir processos ou por outros motivos. Ela é compreendida como a ação verificadora do cumprimento da legislação sanitária ao longo de todas as atividades da cadeia de produção, de distribuição, e de comercialização de forma a assegurar a saúde do consumidor, conforme citado no art. 12 da Portaria n. 1.565, de 26 de agosto de 1994, do Ministério da Saúde, que define o Sistema Nacional de Vigilância Sanitária.

A configuração das infrações à Legislação Sanitária Federal e as respectivas sanções foram aprovadas em 20 de agosto de 1977 através da Lei n. 6.437 do Ministério da Saúde, válida em todo território nacional para os serviços e produtos sujeitos ao controle da Vigilância Sanitária, sem prejuizo das sanções de natureza civil ou penal cabiveis. Esta Lei cita as seguintes penalidades: advertência, multa, apreensão de produtos, interdição de produtos, apreensão de vendas ou fabricação de produto, interdição parcial ou total do estabelecimento, proibição de propaganda, cancelamento de autorização para funcionamento e alvará de licenciamento do estabelecimento. A nivel municipal dispõe-se do Decreto n. 6.235 , de 30 de outubro de 1986, art. 247, que define infração sanitária, como "a desobediência ou a inobservância ao disposto nas normas legais regulamentadoras e outras que, por qualquer forma destinem-se à preservação da saúde".

As sanções e penalidades previstas no Decreto Municipal n. 6.235, de 1986 variam de uma simples advertência descrita no Termo de Visita Sanitária até a interdição total do estabelecimento, passando por intimações para cumprimento de exigências em prazo estabelecido, apreensão de produtos e infrações ou multas, que são rotineiramente aplicadas nas ações fiscais em Vigilância Sanitária. A lavratura, registro e controle de autos de infração, além da cobrança de créditos fiscais aplicadas por infrações à legislação municipal de posturas, são regulamentados e de competência exclusiva da Superintendência do Tesouro Municipal do Rio de Janeiro, razão pela qual não é aplicado o Decreto n. 6.437, de 1977 do Ministério da Saúde, que configura as penalidades ou infrações à legislação Sanitária federal, de caráter sanitário.

$\mathrm{Na}$ área de alimentos, as competências de estabelecer regulamentações sanitárias relacionadas com o controle e registro, dividem-se entre - Ministério da Saúde, representado pela Agência Nacional de Vigilância Sanitária (ANVISA), e o Ministério da Agricultura, Pecuária e Abastecimento, através da Secretaria de Defesa Agropecuária (SDA), sendo que a atuação deste último restringe-se ao controle e fiscalização no campo e na indústria. As competências de ambos os ministérios são apresentadas no quadro III. Dentre as normas na área da agricultura, podemos citar como principais, a Lei n. 1.283, de 19 de dezembro de 1950 e a Portaria $n$. 544 , de 16 novembro de 1998 . A primeira dispõe sobre a inspeção industrial e sanitária dos produtos de origem animal in natura, ou industrializados, tais como as carnes de animais e seus subprodutos, pescados, leite, ovos, mel e derivados, e a segunda regulamenta o registro e controle de 
bebidas em geral, excluindo as águas de consumo, minerais, adicionadas de sais, que são regulamentadas pela Resolução n. 54, de 15 de junho de 2000 do Ministério da Saúde. Embora leites em geral e laticínios sejam competência da Agricultura, leites para fins especiais, dietas específicas, leites fortificados, para usos especiais, ou ainda fórmulas infantis, são controlados pela Vigilância Sanitária, assim como, qualquer produto alimentício ou matéria-prima alimentar quando exposto à venda ou ao consumo.

\section{Quadro III - Competências normativas para o controle e registro de alimentos e produtos afins nas áreas da saúde e agricultura}

\begin{tabular}{|c|c|}
\hline $\begin{array}{c}\text { Ministério da Saúde } \\
\text { Agência Nacional de Vigilância } \\
\text { Sanitária }\end{array}$ & $\begin{array}{c}\text { Ministério da Agricultura, Pecuária } \\
\text { e Abastecimento } \\
\text { Secretaria de Defesa Agropecuária }\end{array}$ \\
\hline $\begin{array}{l}\text { - Produtos de origem vegetal industriali- } \\
\text { zados; } \\
\text { - Alimentos para fins especiais (dietas, } \\
\text { idosos, gestantes, infantis etc.); } \\
\text { - Suplementos Vitaminicos ou Minerais; } \\
\text { - Farinhas, amidos e féculas, } \\
\text { fortificadas; } \\
\text { - Sopas desidratadas, sobremesas e } \\
\text { pós para preparo de alimentos; } \\
\text { - Pães, massas e produtos de confeitaria; } \\
\text { - Biscoitos, balas e doces; } \\
\text { - Aditivos e coadjuvantes de tecnologia; } \\
\text { - Frutas e hortaliças industrializadas; } \\
\text { - Embalagens e materiais destinados a } \\
\text { entrarem em contato com os alimentos; } \\
\text { - Especiarias e temperos; } \\
\text { - Achocolatados, café, chá e erva-mate; } \\
\text { - Açúcar, sal de mesa, hipossódico e } \\
\text { sucedâneos de sal; } \\
\text { - Águas minerais, e águas adicionadas } \\
\text { de sais, águas potáveis de mesa e } \\
\text { gelo; } \\
\text { - Óleos e gorduras vegetais; outros. }\end{array}$ & $\begin{array}{l}\text { - Produtos de origem animal in natura e } \\
\text { industrializados; } \\
\text { - Mel, própolis e derivados; } \\
\text { - Bebidas alcoólicas; } \\
\text { - Bebidas não alcoólicas e refrigerantes; } \\
\text { - Sucos e néctares; } \\
\text { - Polpas de frutas; } \\
\text { - Pós para refrescos; } \\
\text { - Preparados líquidos para refrescos; } \\
\text { - Vinagres; } \\
\text { - Cereais e leguminosas em grãos; } \\
\text { - Frutas e hortaliças in natura; } \\
\text { - Farinhas e farelos (alimentação animal); } \\
\text { outros. }\end{array}$ \\
\hline
\end{tabular}

Fonte: Leis Federais ns. 1.283/50, 986/69, 9.782/99; Portaria MA n. 544/98, Resoluções MS ns. 23/00 e 54/00. 
De acordo com o exposto percebe-se uma falta de clareza e critérios na definição das competências citadas no quadro III, dificultando a aplicabilidade normativa das ações fiscais na área de alimentos por parte das vigilâncias sanitárias municipais.

A Vigilância Sanitária de Alimentos no Município do Rio de Janeiro na prestação de serviços de promoção, proteção e recuperação da saúde realiza de forma constante a inspeção/fiscalização de estabelecimentos de gêneros alimentícios obedecendo normativas federais e estaduais, aplicando com maior freqüência regulamentos aprovados pelo próprio municipio do Rio de Janeiro, tais como o Decreto n. 6.235, de 1986 e extraindo os documentos legais de caráter orientador, preventivo e punitivo, quando necessário. A autonomia das ações de vigilância sanitária no sentido de preservar a saúde de seus municipes é recente e encontra amparo na Declaração Universal dos Direitos Humanos, bem como nas Constituições Federais anteriores e principalmente na Constituição Federal vigente, conforme destaca Dallari (1991).

Gráfico 1 - Quantitativo de documentos extraídos nas ações fiscais na área de alimentos pela Vigilância Sanitária Municipal do Rio de Janeiro no periodo de 1997 a 2004

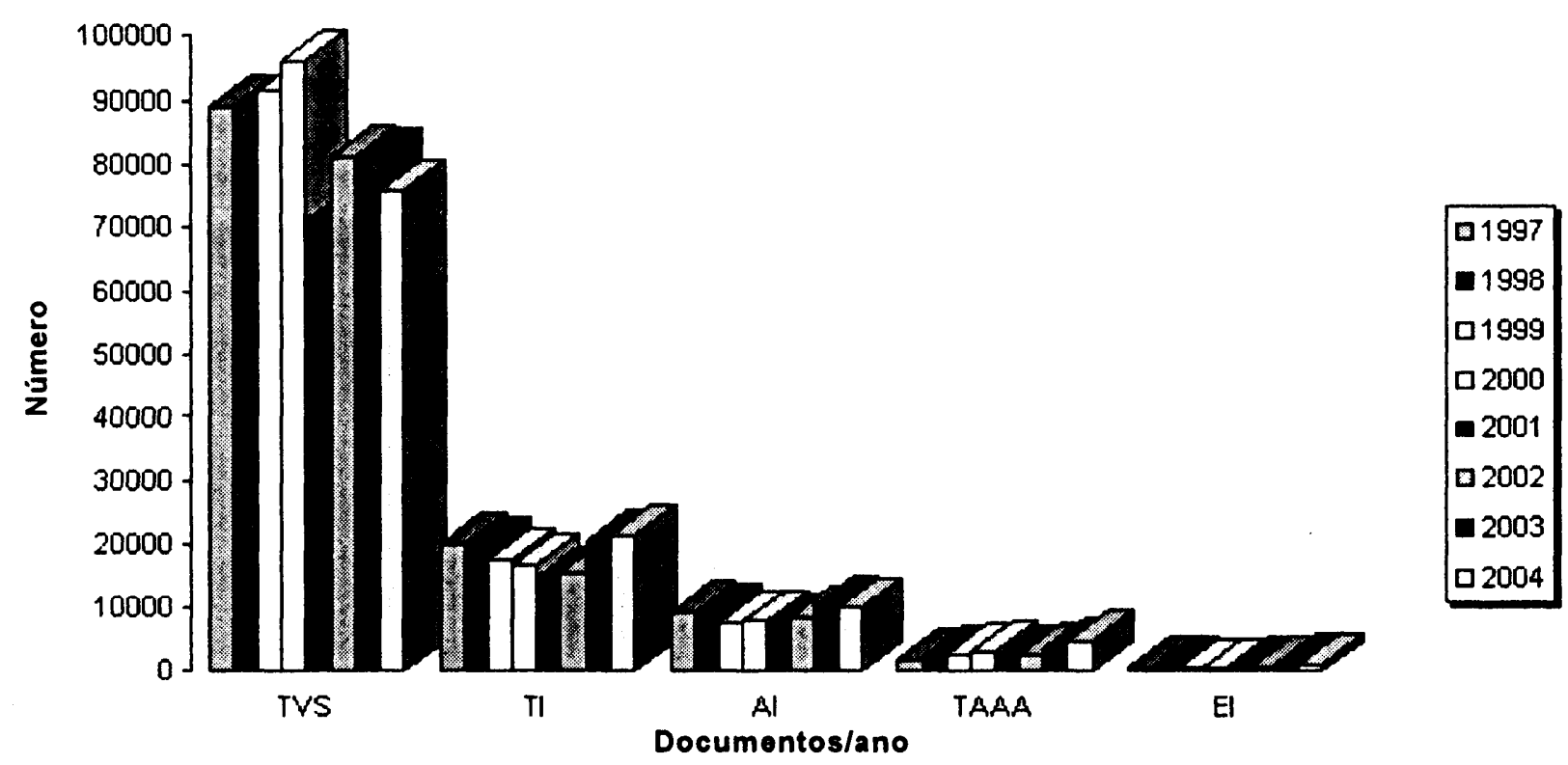

Fonte: Divisão de Apoio Técnico em Vigilåncia e Fiscalização Sanitária do Municipio do Rio de Janeiro. 
Com a finalidade de verificar a aplicabilidade normativa nas ações fiscais da Vigilância Sanitária Municipal do Rio de Janeiro, avaliou-se o número de documentos extraidos nos procedimentos de fiscalização sanitária executados ao longo de oito anos, arquivados na Divisão de Apoio Técnico desta vigilância sanitária. Os resultados deste estudo são apresentados no gráfico 01.

Constata-se através do estudo realizado uma uniformidade na aplicação dos instrumentos de 1997 a 2004, com maior freqüência do Termo de Visita Sanitária, em todos os anos, seguidos do Termo Intimação, dos Autos de Infração e por último dos Termos de Interdição; o que caracteriza uma uniformidade quantitativa de proporcionalidade no decorrer das visitas geralmente realizadas mensalmente nos diferentes estabelecimentos relacionados com alimentos. O fato demonstra o empenho da VISA municipal em pautar suas ações prioritariamente de forma orientadora e em segundo plano com caráter punitivo (Gráfico 01).

A relação entre os três niveis de governo é fundamental para o desenvolvimento das ações inerentes à Vigilância Sanitária em qualquer área, assim como o desenvolvimento de políticas de saúde que facilitem o entendimento quanto às responsabilidades, direitos constitucionais e garantia destes direitos. De acordo com Dallari (1991) "o municipio brasileiro está duplamente titulado para legislar sobre proteção e defesa da saúde". A mesma autora em 2001, ressalta que para que se possa atuar adequadamente em vigilância sanitária, no Brasil, hoje, é indispensável compreender a estrutura institucional onde se enquadra o exercicio dessa atividade. Com a Constituição de 1988, os municipios brasileiros conquistaram uma tríplice autonomia: politica, administrativa e financeira. No entanto, para o adequado desempenho das ações de vigilância sanitária, faz-se necessário a interação com os demais órgãos envolvidos nas mesmas ações ou com competências concorrentes, o compartilhamento de responsabilidades nas diferentes esferas de governo, e a articulação entre as estruturas de: fiscalização/inspeção, registro, análises laboratoriais, investigação das doenças relacionadas com alimentos, e outras. Observando-se a integração das atividades fiscais dos Serviços Federais, Estaduais e Municipais e seus respectivos laboratórios. E no que cabe aos municipios, devem ser estabelecidas normas claras, de modo a facilitar não apenas a execução das atividades-fins, com um mínimo de uniformidade entre as Vigilâncias de caráter executivo, bem como, a avaliação das ações de modo a permitir novos planejamentos estratégicos e um melhor atendimento a demanda da população assistida.

\section{CONCLUSÃO}

Desta forma, a Vigilância Sanitária municipal do Rio de Janeiro apresenta interação e sintonia com os demais órgãos atuantes na Vigilância 
Sanitária nas diferentes esferas de governo compartilhando, portanto, as responsabilidades. Utiliza-se de forma sistemática das disposições normativas sanitárias, empregando os pertinentes instrumentos legais e com a prerrogativa de uma uniformidade anual quantitativa na extração desses documentos, e também na proporcionalidade em relação à extração dos diferentes documentos atendendo os objetivos precipuos da Vigilância Sanitária de prevenir riscos ao consumidor, priorizando ações de caráter preventivo, conforme demonstram Termos de Intimação (TI) extraidos, em detrimento de ações de caráter punitivo, conforme o quantitativo de Autos de Infração e Editais de Interdição aplicados. E por fim, o trabalho conclui na utilização dos atos normativos e das competências normativas para o controle de alimentos, devendo essas disposições normativas sanitárias, apresentar-se, de formas claras e transparentes, direcionando para o órgão competente. A falha desta prerrogativa poderá acarretar dificuldade no desenvolvimento das ações fiscais da Vigilância Sanitária municipal e na proteção da saúde do consumidor.

\section{REFERÊNCIAS}

BRASIL. Ministério da Agricultura, Pecuária e Abastecimento. Lei n. 1.283, de 19 de dezembro de 1950. Dispõe sobre a inspeção industrial e sanitária dos Produtos de Origem Animal. Diário Oficial da União de 19 de dezembro de 1950.

BRASIL. Decreto Federal n. 30.691, de 29 de março de 1952. Aprova o Regulamento da Inspeção Industrial e Sanitária de Produtos de Origem Animal. Diário Oficial da União, 1952.

BRASIL. Ministério da Saúde. Agência Nacional de Vigilância Sanitária. Lei n. 6.437, de 20 de agosto de 1977. Configura infrações à legislação sanitária federal, estabelece as sanções respectivas, e dá outras providências. Diário Oficial da União. 24 de agosto de 1977.

BRASIL. Decreto-lei n. 986, de 21 de outubro de 1969. Institui as Normas Básicas sobre alimentos. Diário Oficial da União, Brasilia, DF, outubro de 1969.

BRASIL. Constituição da República Federativa, promulgada em 5 de outubro de 1988. Brasilia, 1988.

BRASIL. Leis, Decretos etc. - Lei n. 8.080, de 19 de setembro de 1990. Seção I, pt. I, p. 180555-9. Institui o Sistema Único de Saúde. Diário Oficial da União, Brasília 20 de setembro de 1990.

BRASIL. Ministério da Saúde. Portaria n. 1.565, de 26 de agosto de 1994. Define o Sistema Nacional de Vigilância Sanitária e sua abrangência, esclarece a competência das três esferas de governo e estabelece as bases para a descentralização da execução de serviços e ações de vigilância em saúde no âmbito do Sistema Único de Saúde. Diário Oficial da União, Brasilia, DF, 1994. 
BRASIL. Ministério da Agricultura, Pecuária e Abastecimento. Portaria n. 544 , de 16 de novembro de 1998. Aprova os regulamentos técnicos para a fixação dos Padrões de Identidade e Qualidade para refresco, refrigerante, preparado ou concentrado liquido para refresco ou refrigerante, preparado sólido para refresco, xarope e chá pronto para o consumo. Diário Oficial da União de 17 de novembro de 1998.

BRASIL. Lei n. 9.782, de 26 de janeiro de 1999. Define o Sistema Nacional de Vigilância Sanitária, cria a Agência Nacional de Vigilância Sanitária e dá outras providências. Diário Oficial da União de 11 de fevereiro de 1999.

BRASIL. Ministério da Saúde. Agência Nacional de Vigilância Sanitária. Resolução n. 54, de 15 de junho de 2000. Dispõe sobre o Regulamento Técnico para Fixação de Identidade e Qualidade de Água Mineral Natural e Água Natural. Brasilia, Diário Oficial da União, 19 de junho de 2000.

BRASIL. Ministério da Saúde. Agência Nacional de Vigilância Sanitária. Resolução n. 23, de 15 de março de 2000. Dispõe sobre o Manual de Procedimentos Básicos para Registro e Dispensa da Obrigatoriedade de Registro de Produtos Pertinentes à Área de Alimentos. Brasilia, Diário Oficial da União, 16 de março de 2000.

CARTANA, A. P. Processo Administrativo Sanitário: Teoria e Prática. Porto Alegre: Editora Alcance, 2000, p. 240.

CARVALHO, C.; MACHADO, R. B.; TIMM, L. B. Direito Sanitário Brasileiro. São Paulo: Ed. Quartier Latin, 2004, p. 12-13, p. 350.

COSTA, E. A. e ROZENFELD, S. Constituição da Vigilância Sanitária no Brasil, p. 15. In: S. Rozenfeld (org.) Fundamentos da Vigilância Sanitária. Rio de Janeiro: Editora FIOCRUZ, 2000.

CRETELLA Jr., J. Direito Administrativo Municipal. 2. ed., Rio de Janeiro: Forense, 1981, p. 332-339.

CUNHA, S. S. Dicionário compacto do direito. São Paulo: Saraiva, 2003.

DALLARI, S. G. O papel do Municipio no desenvolvimento de políticas de Saúde. Revista de Saúde Pública, v. 25, n. 5, p. 401-405, 1991.

Vigilância Sanitária, Direito e Cidadania. Caderno de Textos da Conferência Nacional de Vigilância Sanitária, Brasilia, 2001, p. 109-127. MEIRELLES, H. L. Direito Administrativo Brasileiro. 18. ed., São Paulo: Malheiros, 1993, p. 161-167.

RIO DE JANEIRO (Estado). Decreto n. 6.538, de 17 de fevereiro de 1983. Regulamento so: re Alimentos, Higiene e Fiscalização. Diário Oficial do Estado do Rio de Janeiro. 1983.

RIO DE JANEIRO (Município). Decreto Municipal n. 6.235, de 30 de outubro de 1986. Aprova o Regulamento da Defesa e Proteção da Saúde no tocante a alimentos e à Higiene Habitacional e Ambiental. Diário Oficial do Municipio, 1986. 
RIO DE JANEIRO (Municipio). Resolução Municipal Secretaria Municipal de Saúde n. 492, de 19 de outubro de 1994. Aprova e adota oficialmente o Termo de Visita Sanitária e institui normas para sua utilização. Diário Oficial do Município do Rio de Janeiro, 2 de agosto de 1995.

ROSENFELD, S. Fundamentos da Vigilância Sanitária. Rio de Janeiro: Editora FIOCRUZ, 2000.

SILVA, S. F. Municipalização da Saúde e Poder Local. Sujeitos, Atores e Políticas, São Paulo: Hucitec, 2001. 